Abstracta Iranica Abstracta Iranica

Revue bibliographique pour le domaine irano-aryen

Volume 42-43 | 2021

Comptes rendus des publications de 2019-2020

\title{
Jörg Ahrnt. Royal tomb, never finished, mit einer Einleitung von Harald Schulze und Barbara Helwing
}

\section{Rémy Boucharlat}

\section{(2) OpenEdition \\ Journals}

Édition électronique

URL : https://journals.openedition.org/abstractairanica/52549

DOI : 10.4000/abstractairanica.52549

ISSN : 1961-960X

Éditeur :

CNRS (UMR 7528 Mondes iraniens et indiens), Éditions de l'IFRI

Référence électronique

Rémy Boucharlat, « Jörg Ahrnt. Royal tomb, never finished, mit einer Einleitung von Harald Schulze und Barbara Helwing », Abstracta Iranica [En ligne], Volume 42-43| 2021, document 38, mis en ligne le 15 avril 2021, consulté le 12 décembre 2022. URL : http://journals.openedition.org/abstractairanica/ 52549 ; DOI : https://doi.org/10.4000/abstractairanica.52549

Ce document a été généré automatiquement le 12 décembre 2022.

Tous droits réservés 


\title{
Jörg Ahrnt. Royal tomb, never finished, mit einer Einleitung von Harald Schulze und Barbara Helwing
}

\author{
Rémy Boucharlat
}

\section{RÉFÉRENCE}

Jörg Ahrnt. Royal tomb, never finished, mit einer Einleitung von Harald Schulze und Barbara Helwing, AMIT 48, 2017 [paru 2019], p. 307-317.

1 L'auteur de cet article particulier est un ami de la famille de Friedrich Werner von Schulenburg, qui fut ambassadeur d'Allemagne en Iran au début des années 1930. Antinazi, ce diplomate devait être exécuté après le10 juillet 1944. Parmi ces échanges épistolaires nombreux avec E. Herzfeld, une lettre de ce dernier du 22 septembre 1932 donne quelques indications sur la fouille d'une «tombe inachevée » près de Persépolis. Il s'agit de la plinthe à trois degrés de Takht-i Rustam dans laquelle Herzfeld voyait, avec raison, les similitudes avec le soubassement de la tombe de Cyrus à Pasargades. Pour lui, elle était la tombe inachevée de Cambyse, hypothèse unanimement cceptée jusqu'à ces dernières années. L'autre hypothèse plus actuelle est d'y voir la tombe, achevée, de Hystaspe père de Darius.

2 La lettre confirme l'existence de deux fosses funéraires ainsi qu'un bijou et de la poterie. Elle indique que le démontage et remontage ont été assurés avec soin par F. Krefter. Herzfeld, qui n'a jamais publié cette fouille, pas plus que ses autres travaux à Persépolis, a cependant laissé un croquis minutieux, seul élément de rapport de fouille. 


\section{AUTEURS}

\section{RÉMY BOUCHARLAT}

UMR 5133 CNRS-Université de Lyon 